\title{
The Ups and Downs of Volcanic Unrest: Insights from Integrated Geodesy and Numerical Modelling
}

\author{
J. Hickey, J. Gottsmann, P. Mothes, H. Odbert, I. Prutkin \\ and P. Vajda
}

\begin{abstract}
Volcanic eruptions are often preceded by small changes in the shape of the volcano. Such volcanic deformation may be measured using precise surveying techniques and analysed to better understand volcanic processes. Complicating the matter is the fact that deformation events (e.g., inflation or deflation) may result from magmatic, non-magmatic or mixed/hybrid sources. Using spatial and temporal patterns in volcanic deformation data and mathematical models it is possible to infer the location and strength of the subsurface driving mechanism. This can provide essential information to inform hazard assessment, risk mitigation and eruption forecasting. However, most generic models over-simplify their representation of the crustal conditions in which the deformation source resides. We present work from a selection of studies that employ advanced numerical models to interpret deformation and gravity data. These incorporate crustal heterogeneity, topography, viscoelastic rheology and the influence of temperature, to constrain unrest source parameters at Uturuncu (Bolivia), Cotopaxi (Ecuador), Soufrière Hills (Montserrat), and Teide (Tenerife) volcanoes. Such model complexities are justified by
\end{abstract}

J. Hickey and H. Odbert, previously at School of Earth Sciences, University of Bristol, UK.

J. Hickey $(\bowtie)$

Camborne School of Mines, University of Exeter, Exeter, UK

e-mail: J.Hickey@exeter.ac.uk

J. Gottsmann

School of Earth Sciences, University of Bristol, Bristol, UK

J. Gottsmann

Cabot Institute, University of Bristol, Bristol, UK

P. Mothes

Instituto Geofísico, Escuela Politecnica Nacional, Quito, Ecuador
H. Odbert

Met Office, Exeter, UK

I. Prutkin

Institute of Geosciences, Jena University, Jena,

Germany

P. Vajda

Earth Science Institute, Slovak Academy of

Sciences, Bratislava, Slovakia 
geophysical, geological, and petrological constraints. Results highlight how more realistic crustal mechanical conditions alter the way stress and strain are partitioned in the subsurface. This impacts inferred source locations and magmatic pressures, and demonstrates how generic models may produce misleading interpretations due to their simplified assumptions. Further model results are used to infer quantitative and qualitative estimates of magma supply rate and mechanism, respectively. The simultaneous inclusion of gravity data alongside deformation measurements may additionally allow the magmatic or non-magmatic nature of the source to be characterised. Together, these results highlight how models with more realistic, and geophysically consistent, components can improve our understanding of the mechanical processes affecting volcanic unrest and geodetic eruption precursors, to aid eruption forecasting, hazard assessment and risk mitigation.

\section{Extended Spanish Abstract}

La deformación volcánica, caracterizada por pequeños cambios medibles en la morfología del volcán, a menudo, pero no siempre, precede a una erupción volcánica. Esta cuestión, sin embargo, se complica por el hecho de que los eventos de deformación (por ejemplo, inflación o deflacción) pueden ser el resultado de una fuente magmática, no magmática o de fuentes mixtas/híbridas. Utilizando tanto la amplitud y patrones espacio-temporales de datos de deformación volcánica registrados, así como la utilización de modelos matemáticos, es posible inferir la ubicación y la fuerza de la fuente impulsora subyacente. Estos métodos pueden proporcionar información esencial para la evaluación y mitigación de riesgos, así como para el pronóstico de erupciones volcánicas. Sin embargo, la mayoría de los modelos genéricos son insatisfactorios en su representación de las condiciones de la corteza en las que reside la fuente. En este trabajo presentamos una selección de estudios que emplean modelos numéricos avanzados para la interpretación de datos de deformación y gravedad. Dichos datos incorporan la heterogeneidad de la corteza, la topografía, la reología inelástica y los efectos termo-mecánicos para constreñir los parámetros asociados a la fuente de perturbación en cuatro sistemas volcánicos. Las complejidades de estos modelos están justificadas por limitaciones geofísicas, geológicas y petrológicas. El estudio realizado en el volcán Uturuncu, localizado en Bolivia, destaca la importancia de la estructura sub-superficial y de los procesos dependientes de tiempo en la fuente para explicar los patrones de deformación espacial-temporal. La combinación de dichos resultados indica un ascenso del magma de tipo diapírico. En el volcán Cotopaxi, localizado en Ecuador, los nuevos modelos de inversión que emplean el Análisis por Elementos Finitos esclarecen la ubicación y el volumen de una intrusión magmática durante un episodio de actividad asísmico y no eruptivo con una baja tasa de suministro de magma. Estos modelos también proporcionan señales observables que podrían estar asociadas con futura actividad volcánica intrusiva o eruptiva. El análisis de la deformación intra-eruptiva en el volcán Soufrière Hills, en Montserrat, 
mostró cómo la inflación registrada podría deberse a una serie de reservorios magmáticos apilados o un depósito alargado verticalmente, debido a respuestas termo-mecánicas de la corteza similares. Las condiciones de falla derivadas para las tasas de suministro de magma y reservorio son consistentes con las restricciones térmicas y mecánicas independientes. Utilizando datos gravimétricos y la curiosa falta de deformación asociada, el estudio en el volcán Teide, en Tenerife, se identifican, de forma separada, las contribuciones de fuentes poco profundas como de aquellas con más profundidad. La interpretación de ambos elementos sugiere que una intrusión magmática profunda activó un sistema hidrotermal superficial localizado encima de ésta, y por lo tanto demuestra un efecto causal de un origen mixto. Estos casos de estudio representan una contribución significativa para la comprensión de los procesos volcánicos durante los periodos de actividad intra-eruptiva y no eruptiva. La combinación de estos resultados enfatiza cómo una mejor parametrización de condiciones mecánicas de la corteza puede alterar fundamentalmente la forma en que el estrés y la tensión se reparten en la sub-superficie. Del mismo modo, una topografía compleja, como es el caso en los estratovolcanes con laderas empinadas, puede afectar la partición de la deformación superficial. Estos dos efectos impactan la inferencia de la localización de las fuentes y presiones magmáticas previo al fallo y la erupción, e indican cómo los modelos genéricos pueden conducir a interpretaciones engañosas debido a la simplificación de inferencias acerca de la corteza y a espacios planos y a medias. Resultados adicionales de la modelización son utilizados para inferir estimaciones cuantitativas y cualitativas de la tasa de suministro de magma y el mecanismo, respectivamente, contribuyendo así al entendimiento de la dinámica del transporte del magma. Además, la inclusión simultánea de datos de gravedad junto a mediciones de deformación, permiten la caracterización de la naturaleza magmática o no magmática de la fuente. Juntos, estos estudios destacan cómo los modelos que cuentan con componentes más plausibles y geofísicamente consistentes, pueden mejorar nuestro entendimiento de los procesos mecánicos que afectan la reactivación volcánica y de precursores geodésicos de erupciones. Estos también proporcionan un marco para ayudarnos a avanzar en el pronóstico de una erupción, así como en la evaluación y mitigación de los riesgos, proporcionando datos cuantitativos derivados de la modelización de mecanismos físicos adecuados y robustos.

\section{Keywords}

Volcano deformation - Gravity - Modelling - Crustal mechanics • Geodesy

\section{Palabras clave}

deformación volcánica $\cdot \operatorname{gravedad} \cdot \operatorname{modelización} \cdot$ mecánica de la corteza $•$ geodesia 


\section{Introduction}

Volcano deformation is a key observable during periods of volcanic unrest, and one of the main tools used to monitor developing crises (Sparks et al. 2012). Non-magmatic causes of volcanic deformation during an unrest period do not involve movement of new magma and are most commonly related to active hydrothermal systems (e.g., Fournier and Chardot 2012; Rouwet et al. 2014, and references therein). Magmatic causes reflect the active migration and accumulation of new magma, with usually deeper origins and wider deformation footprints. Hybrid mechanisms have also been proposed, where contributions from magmatic and hydrothermal systems combine to produce a single complex deformation pattern (Gottsmann et al. 2006a).

A variety of both ground and satellite based geodetic monitoring techniques are used to assess the spatial and temporal evolution of volcanic related surface deformation. The two most common techniques employed today are the Global Positioning System (GPS) and Interferometric Synthetic Aperture Radar (InSAR), which track changes in position due to the ground deforming and complement each other with advantages in their temporal and spatial coverage, respectively. Volcano gravimetry studies, the monitoring and interpretation of continuous or time-lapse spatio-temporal gravity variations, can also provide additional information on any density changes associated with the driving mechanism (Battaglia et al. 2008), and thus enable an estimate of its nature (e.g., magmatic or hydrothermal), which is particularly important in cases where there is no significant (observable) surface deformation.

The magnitude, spatial pattern, and temporal evolution of volcanic deformation can be used to infer the location and 'strength' of a causative subsurface source. These source parameters have important implications for volcanic hazards and risk mitigation. Geodetic data are also a key component in eruption forecasting efforts (e.g.,
Sparks et al. 2012), and constraints on source parameters (e.g., pressure or volume changes) from previous deformation episodes can help to quantitatively improve these forecasts. However, making the transition from surface deformation observations to subsurface source processes requires the use of geodetic models, which demand assumptions about crustal mechanics.

Generic analytical models of volcanic deformation (e.g., Mogi 1958) are often oversimplified and do not capture the intrinsic complexities of subsurface systems, which are essential for reliable assessment of causative processes, and thus eruption forecasting and hazard assessment. They usually represent the Earth's crust as a homogeneous, isotropic, elastic, half-space with a flat, free surface. These assumptions can cause misleading interpretations when compared to numerical models that allow for more realistic crustal conditions (Masterlark 2007). Numerical models of volcanic deformation are thus becoming increasingly popular due to this ability to estimate source parameters in crustal conditions that are beyond the analytical realm. These improvements are synonymous with the recent advances in geodetic monitoring, which deserve a more in-depth analysis than generic analytical models can offer.

The extra complexities that numerical models can account for relate to both the source itself, as well as the crustal rocks in which it resides. The deformation source does not have to be represented as a point or cavity, but can contain its own material properties (e.g., Hickey et al. 2013; Gottsmann and Odbert 2014). Moreover, numerical models can incorporate inferences from other geophysical, geological and petrological observables and thus maintain a higher level of consistency by relaxing some of the assumptions that restrict generic analytical models. For example, this enables the inclusion of subsurface heterogeneity, topography, viscoelastic rheology, and temperature-dependent mechanics (e.g., Hickey et al. 2016, and references therein). Consequently, more robust source parameters and magma transport processes can 
Table 1 Summary of geodetic modelling

\begin{tabular}{l|l|l|l|l|l|l|l|l|l}
\hline Volcano & $\begin{array}{l}\text { Unrest } \\
\text { period }\end{array}$ & FWM & IVM & Data & Topo & CMX & TMX & Model & Ref \\
\hline Uturuncu & $1992-2006$ & $\checkmark$ & - & InSAR & - & $\checkmark$ & - & 2D & Hickey et al. (2013) \\
\hline Cotopaxi & $2001-2002$ & $\checkmark$ & $\checkmark$ & EDM & $\checkmark$ & $\checkmark$ & $\checkmark$ & 3D & Hickey et al. (2015) \\
\hline Soufrière hills & $2003-2005$ & $\checkmark$ & - & cGPS & $\checkmark$ & $\checkmark$ & $\checkmark$ & 2D & $\begin{array}{l}\text { Gottsmann and } \\
\text { Odbert (2014) }\end{array}$ \\
\hline $\begin{array}{l}\text { Central volcanic } \\
\text { complex }\end{array}$ & $2004-2005$ & - & $\checkmark$ & $\begin{array}{l}\text { GPS \& } \\
\text { gravity }\end{array}$ & $\checkmark$ & - & - & 3D & Prutkin et al. (2014) \\
\hline
\end{tabular}

FWM forward modelling, IVM inverse modelling, Topo topography, CMX crustal mechanics, TMX thermomechanics, $2 D$ two-dimensional axisymmetric, $3 D$ three-dimensional, Ref reference

be inferred, thereby improving the understanding of the links between deformation and eruption.

In this chapter we summarise the key findings from investigations of a variety of unrest episodes at a selection of the VUELCO target volcanoes; Cotopaxi (Ecuador), Soufrière Hills (Montserrat, British West indies) and the Central Volcanic Complex on Tenerife (Spain), as well as at Uturuncu volcano in Bolivia (Table 1). These examples highlight not only different timescales of unrest and spatial patterns of volcano deformation, but also the influence of crustal mechanical heterogeneity, thermal effects, and topography, on observed signals. The unrest episodes are investigated using both forward and inverse numerical modelling procedures and demonstrate the process of interpreting different geodetic data sets to constrain realistic source parameters. Thus, the purpose of this chapter is not to provide a detailed treatment of the mathematical and numerical approaches. Instead, it is intended to provide the reader with a general overview of the use of advanced numerical models to infer volcanic unrest driving mechanisms with realistic source characteristics.

\section{Implementing Complex Crustal Mechanics}

One of the most important aspects of a deformation model is the representation of crustal mechanics. This has a fundamental control on the way in which stress and strain is distributed and transferred through the Earth's crust, from the source to the surface. In this regard, as briefly mentioned above, generic analytical models are limited by their necessary assumptions of homogeneous and elastic conditions throughout the entire model domain. In reality, the Earth's crust is known to be layered, and volcanic regions in particular can have wide-ranging regions of stiff (high Young's Modulus) and soft (low Young's Modulus) rocks relating to the type of volcanic deposit that formed them, e.g., lava flows (stiff) compared to tuffs (soft) (Gudmundsson 2011). This is what we call subsurface heterogeneity. Where stiff and soft regions are adjacent in the crust, complex subsurface partitioning alters the way stress and strain are transferred to the surface. The outcome is a different surface deformation pattern compared to one that would be seen if the crust was in fact homogeneous. Consequently, generic analytical models restricted to homogeneous crustal mechanics will not adequately represent likely subsurface conditions, and the inferred source parameters from these models can be misleading.

Seismic studies are capable of delineating areas of relatively high and low seismic velocities. They can be used to estimate the dynamic Young's Modulus, $E_{D}$, Poisson's Ratio, $v$, and density, $\rho$, of the crust (Brocher 2005):

$$
v=0.5 \times\left[\left(\frac{V_{P}}{V_{S}}\right)^{2}-2\right] /\left[\left(\frac{V_{P}}{V_{S}}\right)^{2}-1\right]
$$




$$
\begin{gathered}
\rho=1.6612 V_{P}-0.4721 V_{P}^{2}+0.067 V_{P}^{3} \\
-0.0043 V_{P}^{4}+0.000106 V_{P}^{5} \\
E_{D}=\frac{V_{P}^{2} \rho(1+v)(1-2 v)}{(1-v)}
\end{gathered}
$$

where $V_{P}$ and $V_{S}$ are the primary and shear seismic velocities, respectively. The static Young's Modulus, E, is usually a factor of 2-9 smaller than $E_{D}$, and is more appropriate for deformation studies as the dominant processes taking place are significantly slower than the propagation of seismic waves (e.g., Gudmundsson 2011, and references therein). Numerical approaches can incorporate these spatially-variable calculations of Young's Modulus and Poisson's Ratio by allowing the mechanical parameterisation of the crust to vary within the model (Hickey and Gottsmann 2014). This can be achieved in one-dimension, where the values are only changed with depth, or in three-dimensions, where the mechanical representation additionally changes in the two horizontal axes. The Finite Element Method is the most common technique used when incorporating subsurface heterogeneity. With this approach, a heterogeneous model domain can be built using multiple different sized homogeneous 'blocks' of varying material properties (Hickey et al. 2013), with continuous interpolations as a function of depth or distance (Gottsmann and Odbert 2014), or with a three-dimensional coordinate interpolation (Hickey et al. 2016).

A further advantage of a numerical approach using the Finite Element Method is the ability to include a spatially variable inelastic rheology that is dependent on an estimated temperature distribution. Rocks do not always behave in an elastic manner (Ranalli 1995). Instead, where crustal conditions are hotter than the brittle-ductile transition, or subject to long-term loading, rocks can deform like very high viscosity fluids, and so viscoelastic effects are more likely (Ranalli 1995). This is especially important when a hot magmatic component is assumed to be present, or where elevated geothermal gradients are observed. Also, when models are restricted to elastic mechanical behaviour it can be difficult to constrain realistic source processes, particularly if there is a complex temporal deformation pattern that can not be reproduced with the instantaneous elastic stress-strain relationship, and may be better represented by a non-instantaneous viscous stress response. A model that incorporates temperature-dependent mechanics can overcome these difficulties. This is achieved using the Finite Element Method with a two-step procedure (Hickey and Gottsmann 2014). First, a spatially-variable, stationary, temperature distribution is derived, primarily dependent on the local geothermal gradient(s) and an assumed (magmatic) source temperature. This temperature distribution, $T$, is then used to define a crustal viscosity, $\eta$, for example through an Arrhenius relationship, where:

$$
\eta=A_{d} \exp \left(\frac{H}{R T}\right)
$$

and $A_{d}$ is the Dorn Parameter, $H$ is the activation energy, and $R$ is the universal gas constant. The viscosity is used in a viscoelastic material representation (Hickey and Gottsmann 2014), so where the viscosity is high the material response is dominated by elastic behaviour, and when the viscosity is lower the rocks show an increasingly higher tendency for viscous behaviour. To demonstrate the effect of temperature-dependent mechanics, and subsurface heterogeneity, the following case studies include examples of both.

\section{Case Studies}

\section{Uturuncu}

Uturuncu volcano is located in southern Bolivia, within the Altiplano-Puna Volcanic Complex. It has been steadily inflating since at least 1992 (Pritchard and Simons 2002), and combined with shallow seismicity and near-summit active fumaroles represents a volcanic system showing significant signs of unrest (Sparks et al. 2008). 
Hickey et al. (2013) focused on the mechanism driving the $70 \mathrm{~km}$ wide region of ground uplift between 1992 and 2006. The aim was to constrain first-order source parameters that explain both the observed uplift rate of 1-2 cm/year and the large spatial deformation footprint (Pritchard and Simons 2002). Stress and strain from pressurised finite sources were solved numerically using Finite Element Analysis, accounting for both homogeneous and heterogeneous subsurface structure in elastic and viscoelastic rheologies. Crustal heterogeneity was constrained from seismic velocity data, which indicates a pervasive large low-velocity zone $\sim 17 \mathrm{~km}$ below the surface. This is deduced to represent one of the world's largest known regions of partial-melt: the Altiplano-Puna Magma Body (APMB) (Sparks et al. 2008).

The comparison between crustal heterogeneity and homogeneity highlights the significant effect of a mechanically weak source-depth layer (Fig. 1). The weak layer, with a lower Young's Modulus, alters surface deformation patterns by accommodating more of the subsurface strain than its surrounding layers, thereby acting as a mechanical buffer. Continuous and regular time-dependent deformation, the long-lived nature of the source, and an anomalously high regional crustal heat-flux break the assumption of elastic conditions (e.g., Ranalli 1995), so a viscoelastic crustal rheology was tested, using the standard linear solid representation (e.g. Hickey and Gottsmann 2014). The elastic models could also only account for the spatial component of the observed uplift so their results were used solely to guide the parameters tested in the viscoelastic models. A range of possible source geometries were assessed, but spherical and oblate shapes were rejected on the grounds of their depth below the APMB and likely unsustainable pressurisation given the expected crustal mechanics. This left a prolate shaped source, whose minimum size was determined using maximum laboratory values for host-rock tensile strength. The final preferred model suggests that temporally-continuous pressurisation of a magma source protruding from the top of the APMB is causing the observed spatial and temporal surface uplift, whereas the previous models could only infer that a simple-geometry source was being pressurised somewhere within the APMB (Pritchard and Simons 2002). Hence, this also demonstrates how a pressure-time function plays a first-order role in explaining time-dependent deformation.

Simultaneous work on an extended InSAR data set shows how the central uplift region at Uturuncu is surrounded by a 'moat' of subsidence (Fialko and Pearse 2012). To explain this observation they also constrained a model where magma rises out and up from the APMB with a diapiric-type ascent mechanism. Further evidence for this magmatic process is available through a complementary gravimetric study (del Potro et al. 2013). Therefore, this highlights how combinations of geodetic data and numerical models can not only constrain more plausible deformation source parameters, but can also infer magma transport dynamics.

\section{Cotopaxi}

Cotopaxi is a large, glacier-clad stratovolcano situated in the Eastern Cordillera of the Ecuadorian Andes. The $1 \mathrm{~km}^{3}$ glacier presents a substantial lahar risk to people in the surrounding areas, and particularly to the 100,000 inhabitants that reside in the path of the 1877 lahar which descended the Inter-Andean Valley (Pistolesi et al. 2013).

Unrest was detected at Cotopaxi in 2001 and 2002. There was a significant increase in the amount of volcanic seismicity in the NE quadrant of the volcano, and this was originally interpreted to represent a dyke intrusion with subsequent gas-release and resonance of the crack (Molina et al. 2008). Hickey et al. (2015) revisited this unrest period, but approached it from a volcano deformation viewpoint. Analysis of an electronic distance meter (EDM) network over the 20012002 period also indicated an asymmetric inflation of the edifice that accompanied the recorded seismicity (Fig. 2). However, the irregular 

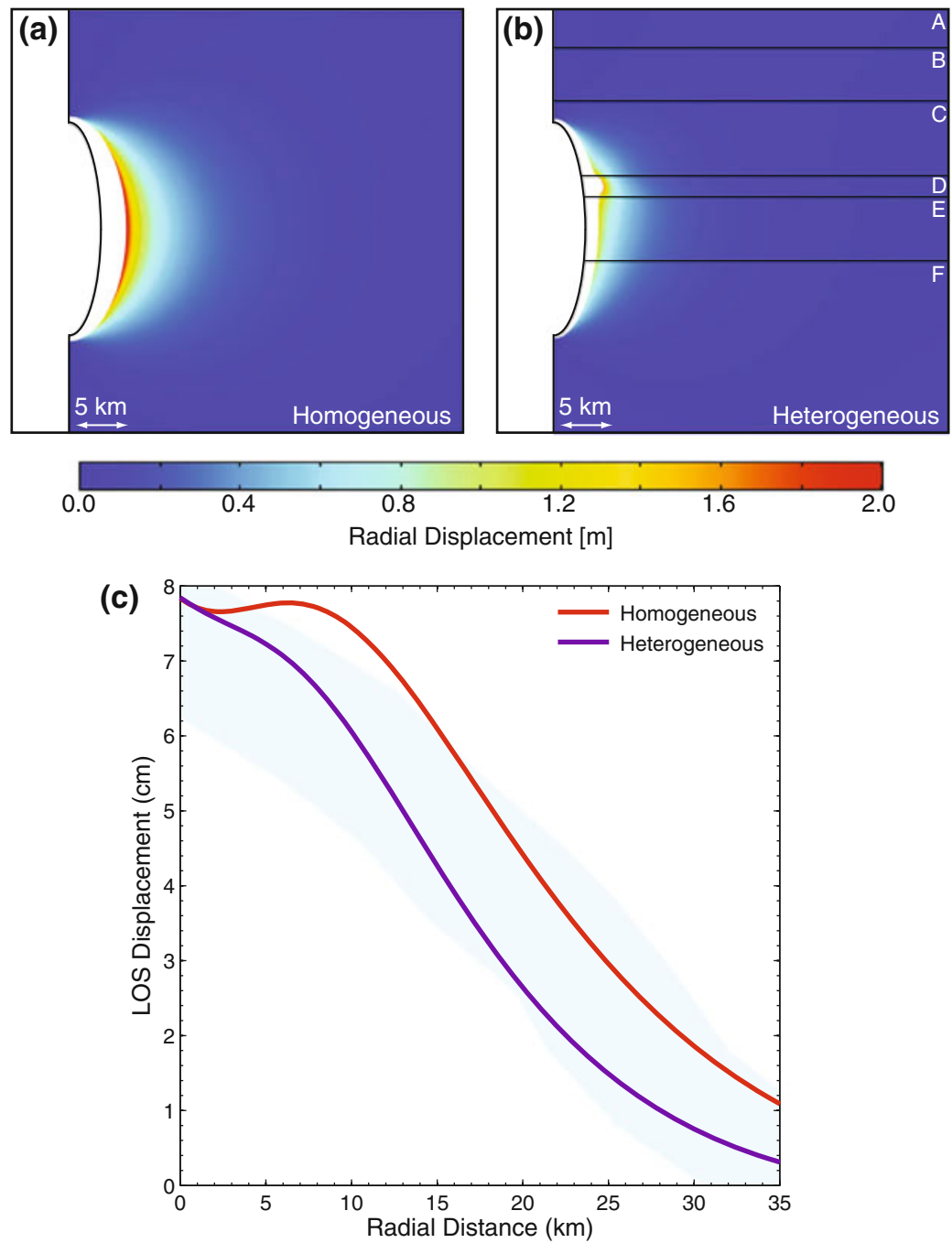

Fig. 1 A comparison of the effect crustal heterogeneity for the same prolate source geometry and depth. a, b The effect of a source depth soft layer on the subsurface deformation of a source. Both panels show the same source, embedded in a homogeneous (a) or heterogeneous domain (b). Colours relate to the radial displacement, and the white shape shows the exaggerated outline of the deformed source after the pressure is applied. In the heterogeneous model the source preferentially deforms

acquisition in time of the EDM data prevented any systematic comparison between the two data sets. To solve for the optimum deformation source parameters, Hickey et al. (2015) implemented a novel numerical inversion procedure using Finite Element models. This is the first into the softer layer (D), compared to the homogeneous medium, which exhibits a concentric deformation pattern. c Modelled surface displacement profiles from the homogeneous (a) and heterogeneous (b) models. The subsurface layering in $\mathbf{b}$ alters the displacement pattern produced at the surface as the soft layer modifies the subsurface strain partitioning. The blue shaded area represents the observed InSAR data and its estimated error bounds

volcanic deformation inversion study to explicitly account for both subsurface heterogeneity and surface topography while searching for a best-fit solution with a range of source shapes. The method works by solving for the predicted EDM deformation with an initial model and 
source configuration. It then continually changes the source location and/or overpressure, within some predefined parameter limits, to minimise the misfit to the recorded EDM data (Fig. 2). After each inversion, the parameter limits (e.g., $\mathrm{X}$ and $\mathrm{Y}$ coordinates) are reduced around the previous solution to produce a set of decreasing size 'Russian-doll-like' parameter constraint grids that ensure a robust solution. Within this workflow, the Finite Element model geometry and mesh are automatically rebuilt, removing the need for repeated manual editing.

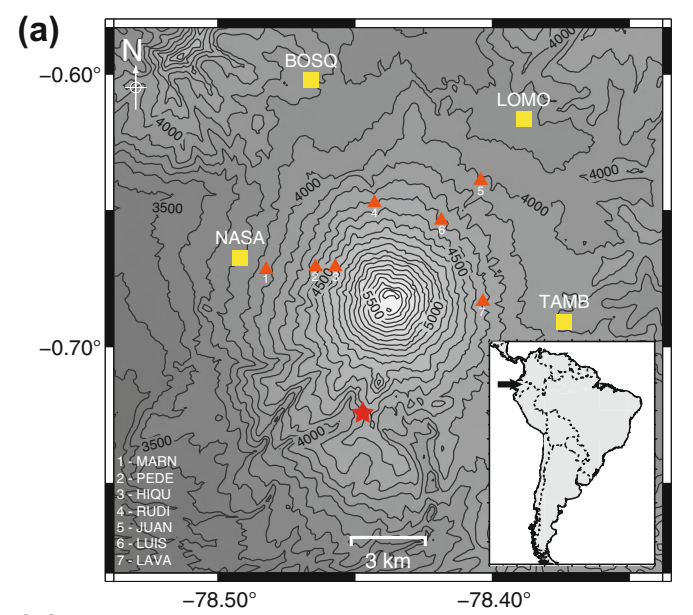

(c)

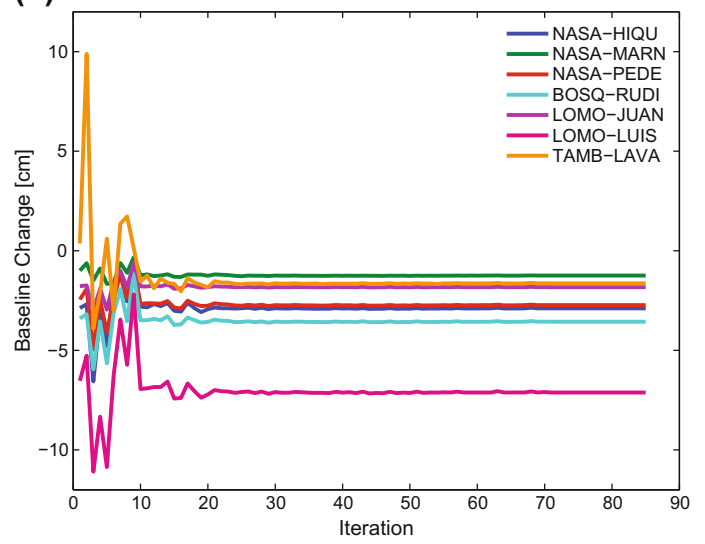

Fig. 2 Deformation and modelling results from Cotopaxi volcano. a Map of the EDM network operational between 2001 and 2002 around the summit of the volcano, with the best-fit source from the Finite Element inversions indicated by a red star. The yellow squares represent the EDM base-stations and the orange triangles are the reflecting prisms. The inset map and arrow shows the location of Cotopaxi within Ecuador, South America.
The inversion models converge on a shallow source beneath the SW flank. The individual best-fit model is inferred to represent a small oblate-shaped magmatic reservoir, approximately $4-5 \mathrm{~km}$ beneath the summit, with a volume increase of roughly $20 \times 10^{6} \mathrm{~m}^{3}$. A deformation source location in the SW is substantially different to the NE location proposed by Molina et al. (2008) when explaining the recorded seismicity. Despite this, when the deformation source was restricted to the NE quadrant the predicted

(b)

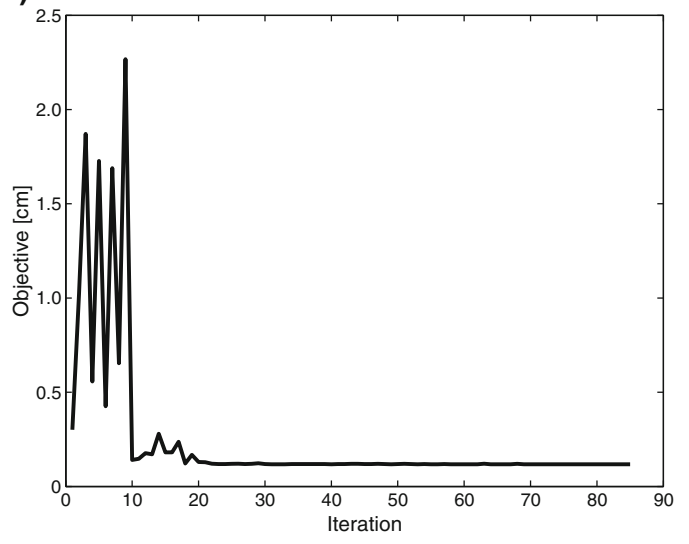

(d)

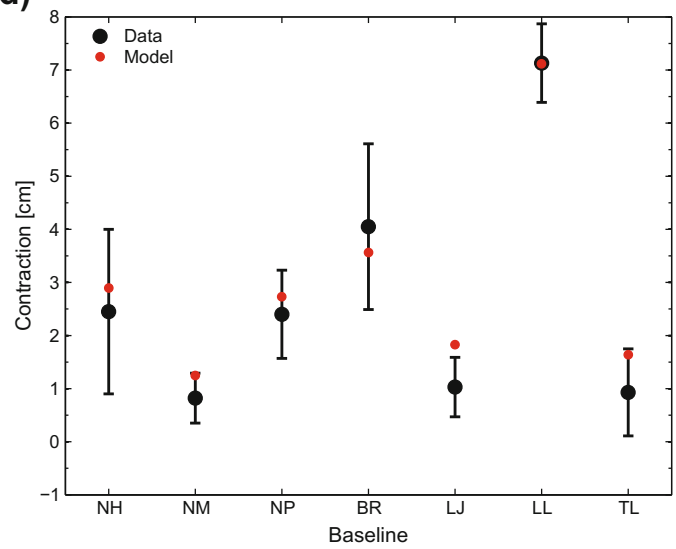

b The variation, and eventual reduction, of the misfit objective function with each iteration from the final, best-fit Finite Element inversion model. c The modelled values from the final inversion for the EDM baseline changes converge to their near-absolute values after approximately 25 iterations. d The best-fitting model (red circles) fits six out of seven of the EDM observations (black circles with error bounds) 
EDM measurements had a very poor fit to the observed data.

To clarify the difference in source location between the seismic and geodetic studies, Hickey et al. (2015) applied the best-fit source parameters from the elastic inversion models in a suite of temperature-dependent viscoelastic forward models to assess the rheology of the host-rock for a range of thermal parameters. The results indicated the most likely subsurface conditions would have promoted a large component of viscous deformation and that the deformation source in the SW would have consequently been pressurised aseismically. Fluid migration from the SW along existing NNE-SSW trending faults could have then caused the observed seismicity in the NE due to mass transport and excess pore pressures. The lack of eruption following this 2001-2002 unrest period and the aseismic nature of the event suggests that the magma supply rate for this period was low. A higher magma supply rate during a future unrest period would be more likely to produce seismicity around the reservoir, and could possibly indicate a level of unrest that signifies an increased likelihood of a forthcoming eruption.

\section{Soufrière Hills}

Starting its latest eruptive episode in 1995 and displaying a remarkable diversity of eruptive activity, Soufrière Hills volcano (SHV) on Montserrat (British West Indies) is one volcano where a correlation between observed deformation and subsequent eruption can be directly established. Ground deformation data at SHV indicate cyclic behaviour of the andesitic magmatic system from periods of several hours to a few years (Odbert et al. 2014). This section focuses on the analysis of intra-eruptive unrest associated with island-wide ground uplift observed via a network of continuous GPS receivers between 28/07/2003 and 01/08/2005 (Odbert et al. 2014). After a major lava dome collapse in 2003, which marked the end of the second phase of dome extrusion at SHV, this period preceded a restart of eruptive activity and renewed dome extrusion in August 2005.

Gottsmann and Odbert (2014) developed numerical models to test for the influence of temperature- and time-dependent stress evolution in a mechanically heterogeneous crust to explain the deformation data. Full details on the model setup and parameter derivation are given in Gottsmann and Odbert (2014) and not repeated here. They implemented two types of magma reservoir model. The first explored a series of pressurising, vertically-stacked reservoirs as proposed by Hautmann et al. (2010), while the second explored the time-dependent pressurisation of a single, vertically-elongated reservoir. Due to a similar temperature distribution from both the stacked and single reservoirs, and similar resultant rheological crustal properties, both suites of models provided equally good fits to the observed ground deformation. The study could hence not discriminate between pressurisation in a magmatic plumbing system consisting of either a single vertically elongated reservoir or a series of stacked reservoirs. Reservoir pressure changes between 4 and $7 \mathrm{MPa}$, for volumes between 60 and $100 \mathrm{~km}^{3}$ and magma compressibility between $4 \times 10^{-11}$ and $1 \times 10^{-9} \mathrm{~Pa}^{-1}$, provided plausible thermomechanical model parameters to explain the deformation data. The associated magma volume fluxes are between 0.015 and $0.021 \mathrm{~km}^{3} /$ year and match those derived from thermal modelling of active sub-volcanic systems (Annen 2009). Introducing a deep-crustal hot zone in the model, which modulates the partitioning of strain into the hotter underlying crust beneath the reservoir(s), promotes a further reduction in reservoir overpressures to values of around 1-2 MPa upon reservoir failure (Fig. 3). These pressure changes are significantly lower than those derived from models assuming a mechanically homogeneous and elastic crust. The deduced overpressures match those for sudden and rapid transcrustal reservoir activation prior to explosions at SHV from the analysis of volumetric strain data (Hautmann et al. 2014). The emerging eruption model at SHV hence involves the periodic failure of a compressible magma mush column beneath the volcano. 
(a)

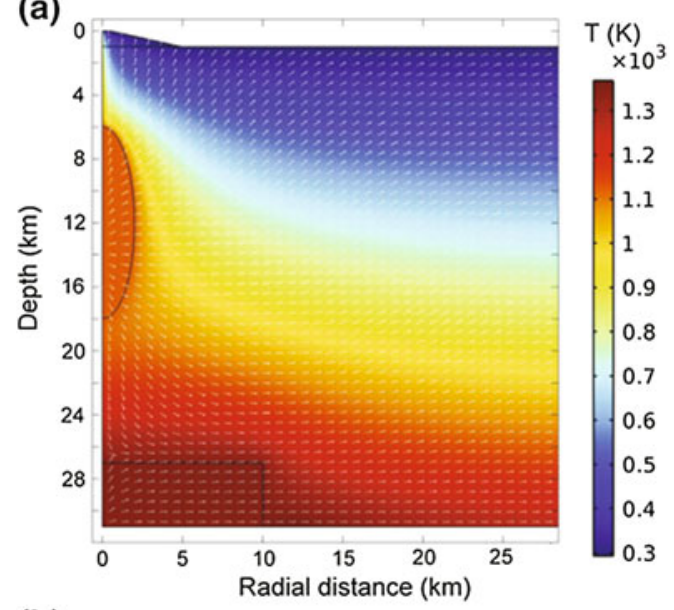

(b)

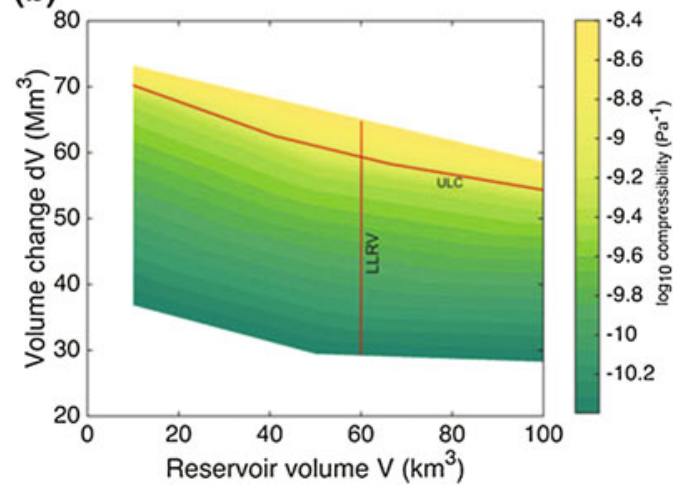

Fig. 3 a The temperature distribution (in K) of the 2-D axisymmetric model domains, caused by a combination of a basal heat flux, the heat from the plumbing system (magma reservoir plus feeder pipe), and a deep-crustal hot zone. Background thermal distribution in the far field is caused exclusively by a basal heat flux of $0.09 \mathrm{~W} / \mathrm{m}^{2}$. Arrows indicate deformation of the medium by reservoir pressurisation. Substantial deformation is accommodated by hot and ductile parts of the mid and lower crust. $\mathbf{b}$ The model parameter space for reservoir volume, volume change, and magma compressibility (shown in log units on the colour bar) from the best fit model solutions to the 2003-2005 intra-eruptive deformation time series at Soufrière Hills Volcano. The overall fit quality decreases substantially toward higher compressibility (order $\left.10^{-9} \mathrm{~Pa}^{-1}\right)$ and toward smaller reservoir volumes $\left(<50 \mathrm{~km}^{3}\right)$. The preferred parameter space is encompassed between the mapped upper limit of compressibility (ULC) and the lower limit of the magma reservoir volume $(L L R V)$

\section{Las Cañadas}

The Las Cañadas caldera (LCC) hosts the central volcanic complex (CVC) on Tenerife (Canary Islands), which includes the twin-volcanoes of Pico Viejo (PV) and Pico Teide (PT). Volcanic unrest on Tenerife started in April 2004 and ended a period of quiescence after the most recent magmatic eruption on the island in 1909. The unrest was geophysically characterised by anomalous seismic activity including a number of felt earthquakes and significant changes in the acceleration of gravity, yet, an absence of significant ground deformation (Gottsmann et al. 2006b). The initial interpretation of the gravity changes by Gottsmann et al. (2006b) pointed towards shallow ( $\sim 2 \mathrm{~km}$ depth) fluid migration as the main source of the unrest, possibly related to a magma intrusion at greater depth. As part of the VUELCO project, Prutkin et al. (2014) revisited the microgravity data recorded between May 2004 and July 2005 and inverted the spatio-temporal residual gravity changes for the gravitational attraction of three-dimensional line segments.

The line segments are defined by 7 parameters: two end point coordinates $(\mathrm{X}, \mathrm{Y}, \mathrm{Z})$ and a line strength (see Table 2). The latter is a proxy for the amplitude of sub-surface mass change, whereby a "weak" line segment represents a small amount of added mass compared to a "strong" line segment of greater added mass. An initial non-linear inversion yielded three line segments of different strengths at depths between $1 \mathrm{~km}$ a.s.l. and $2 \mathrm{~km}$ b.s.l. (i.e. between 1 and $4 \mathrm{~km}$ beneath the surface). Two of the segments were located to the NW of the PV-PT complex, while a third segment was located below the SW rim of the LCC (sources marked Sh 1-3 in Fig. 4). The locations of the segments correspond broadly to zones of heightened seismic activity and the unrest source location identified earlier by Gottsmann et al. (2006b). 
Table 2 UTM coordinates X (Easting in $\mathrm{m}$ ), Y (Northing in $\mathrm{m}$ ), and Z (elevation in $\mathrm{m}$ with respect to sea level) of the end points of the modelled shallow (Sh) and deep (Dp) sources represented by line segments (see Fig. 4)

\begin{tabular}{l|l|l|r|l|l|l|l}
\hline Line segment & X1 & Y1 & Z1 & X2 & Y2 & Z2 & \multicolumn{1}{l}{ M } \\
\hline Sh1 & 327,500 & $3,137,930$ & 1280 & 330,330 & $3,137,260$ & 600 & 0.31 \\
\hline Sh2 & 336,560 & $3,132,050$ & 590 & 334,210 & $3,134,040$ & 420 & 0.83 \\
\hline Sh3 & 335,460 & $3,120,730$ & 1380 & 332,100 & $3,121,210$ & 380 & 0.53 \\
\hline Dp1 & 334,890 & $3,133,910$ & -5440 & 334,630 & $3,134,200$ & -5680 & 7.25 \\
\hline Dp2 & 334,310 & $3,134,590$ & -5840 & 334,630 & $3,134,200$ & -5680 & 8.24 \\
\hline
\end{tabular}

Mass additions $(\Delta \mathrm{M})$ are given in $10^{10} \mathrm{~kg}$. Data Prutkin et al. (2014)
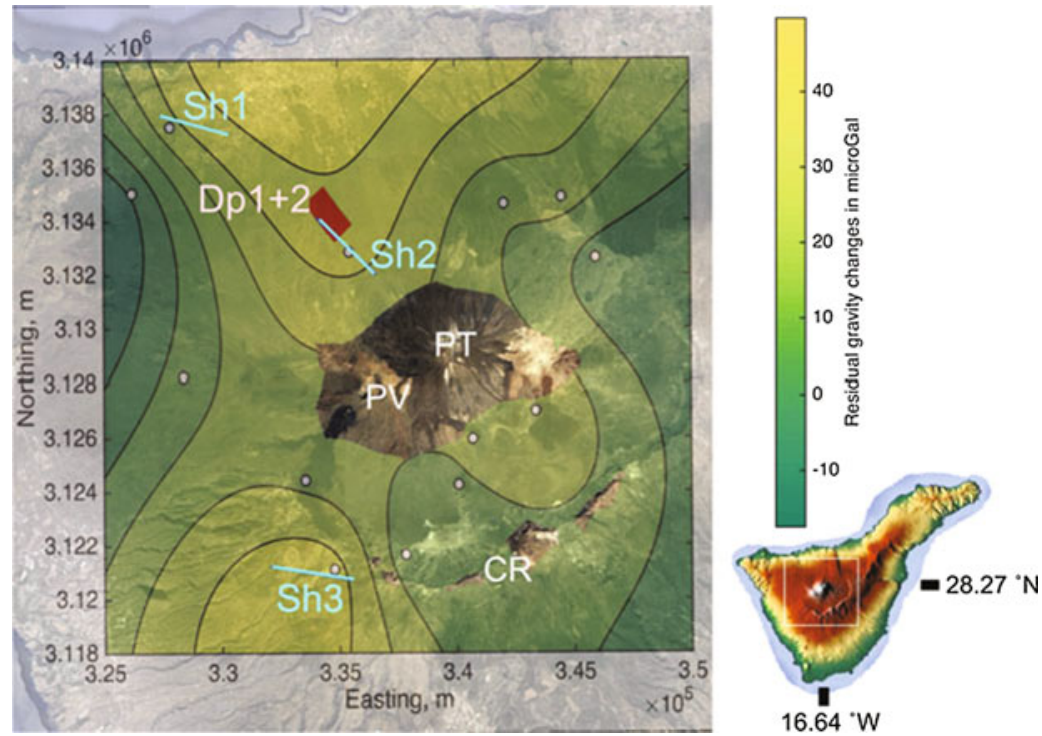

Fig. 4 Location of line segments from gravity data inversion. The figure shows the surface projections of three shallow sources (line segments Sh1-3 in turquoise) and the two deep sources (line segments Dp1 and 2 in red) superimposed over a Google Earth image of the Central Volcanic complex of Tenerife island (Spain). The source locations are derived by a nonlinear inversion of spatiotemporal residual gravity changes shown by coloured contours (in $\mu \mathrm{Gal}$ ) observed between 2004 and 2005 (see Prutkin et al. (2014) for details on inversion routine). The thickness of a line segment is indicative of the "strength" of the deduced mass change; i.e., the

However, closer inspection of the initial inversion results revealed that the line segments represent the superposition of deep and shallow seated sources. The decomposition of the gravity change data into shallow and deep fields (see Prutkin et al. 2014 for details) provided the basis amount of added mass. The mass added to the deep sources is more than 10 times higher than to the shallow sources. Line segments Sh1-3 are interpreted to represent near-surface sources in the NW and SW part of the Pico Teide (PT; $3718 \mathrm{~m}$ a.s.1.) and Pico Viejo (PV; $3135 \mathrm{~m}$ a.s. 1.) volcanic complex, associated with fluid migration as a result of an intrusion of magma at around $5.8 \mathrm{~km} \mathrm{b.s.1.}$ (Dp sources). See Table 2 for details on segments and associated mass changes. The southern caldera rim $(C R)$ is shown for reference and the inset shows a digital elevation model of Tenerife, with the study area identified by a white rectangle

for the separate inversions of the two fields using the three-dimensional line segment approximation. The deep field inversion constrained two connected and strong line segments at a depth of about $5.8 \mathrm{~km}$ b.s.1. (marked Dp1 and Dp2 in Fig. 4), while the inversion of the shallow field 
identified three similarly weak line segments situated at near-surface depths $(<2 \mathrm{~km}$ from ground surface; see Fig. 4 and Table 2).

The most plausible interpretation of the inversion results is that the weak line segments represent sources dominated by hydrothermal fluids. In contrast, the deeper-seated sources can be interpreted as parts of an intrusion of new magma. This intrusion may have released fluids which consequently migrated towards shallower depths where they excited a shallow hydrothermal system. The geophysical signals resulting from these coupled magmatic-hydrothermal processes point towards a hybrid source nature for the unrest on Tenerife in 2004-2005. The identified link between deep and shallow unrest sources suggests the presence of permeable pathways for shallow fluid migration at the CVC.

\section{Discussion}

\section{The Effect of Crustal Mechanics on Stress, Strain and Pressure}

The presented investigations at Uturuncu, Cotopaxi and SHV all incorporate subsurface heterogeneity, however the effects are somewhat different. At Cotopaxi the final inferred deformation source is shallow, at a level where the model does not incorporate substantial heterogeneity due to the limited amount of available seismic data. Hence, with this model configuration, the heterogeneity has not played a significant role in altering the location of the source. It is likely, however, that in reality the volcanic edifice and shallow subsurface does have a certain level of heterogeneity. It is therefore possible that had this been taken into account the inferred deformation source might be located more centrally beneath the edifice. Conversely, at Uturuncu and SHV subsurface heterogeneity played a crucial role in determining the deformation source locations. In both cases, the inclusion of vertical layering in the Young's Modulus distribution altered the inferred depth of the source; the heterogeneous models predict deeper sources than the generic homogeneous analytical models.
From this, it also follows that a horizontal variation in mechanical properties would influence the horizontal location of a deformation source (e.g., Hickey et al. 2016).

A second effect of subsurface heterogeneity relates to source pressure requirements. It is common with homogeneous crustal mechanics to require unrealistically high source pressurisation (>100's MPa) when attempting to fit an observed deformation signal, yet there is no petrological or mechanical evidence for such conditions. Theoretical work from a mechanical viewpoint suggests that the maximum overpressure a source can sustain without failing is equal to the tensile strength of the host rock (e.g., Gudmundsson 2011). Above this limit, a magmatic reservoir would trigger a dyke intrusion. Work at Uturuncu and SHV shows that elastic heterogeneous deformation models bring source over-pressure requirements more in line with both in situ and laboratory values of tensile strength. This is due to a relative reduction in the average Young's Modulus above the source, compared to a higher homogeneous Young's Modulus through the entirety of the crust, and thus a greater amount of deformation for a given pressure increment. Furthermore, with a maximum value for the source over-pressure, constraints can be placed on the minimum size of a deformation source, given the two are directly linked. This allows, for example, an estimate to be placed on the volume of a magma reservoir. When multiple magmatic sources might be present numerical models can additionally account for stress interactions between the two, something not considered by generic analytical models (Pascal et al. 2013).

As a next step to subsurface heterogeneity, the case studies at Cotopaxi and SHV incorporated temperature-dependent mechanics to evaluate the effect of a viscoelastic rheology. At Uturuncu, investigations were also carried out using a viscoelastic rheology without temperaturedependence. In all three cases, a viscoelastic medium reduced the over-pressure requirements further when compared to the purely elastic models. This is due to the viscous expansion that follows an initial elastic inflation. The effect of thermomechanics is greater than just modifying 
source over-pressure requirements, however. Prolonged magma emplacement over thousands to millions of years in active volcanic areas builds up a significant thermal legacy within the crust. This results in elevated geothermal gradients, and in the case of continued active magmatism, deep crustal hot-zones (Annen 2009). These thermal perturbations are significant for the transfer of stress and strain. For example, at SHV, the combined thermomechanical effects of a deep-crustal hot zone and hot encasing rocks around a mid-crustal andesitic reservoir fundamentally alter the time-dependent subsurface stress and strain partitioning upon priming of the magma reservoir. These effects substantially influence surface strains recorded by volcano geodetic monitoring.

\section{Hybrid Unrest and Source Characterisation}

An intrusion of magma commonly leads to the exsolution of fluids upon decompression, and fluid migration (and accumulation) in itself can produce measurable geodetic surface signals (e.g., Fournier and Chardot 2012; Rouwet et al. 2014, and references therein). A deep intrusion of magma, such as the 2004-2005 unrest on Tenerife, may not necessarily lead to observable surface deformation, meaning deformation data on its own can not provide any meaningful insights on the source process(es). In this case, the combination of deformation and gravity surveys allowed the characterisation of the unrest sources in much greater detail owing to their density contrasts, relative depths and mass additions. This highlights that, especially for the case of hybrid mechanisms where both magmatic and hydrothermal components are present, multi-disciplinary geodetic surveys can provide valuable information on source characterisation to help distinguish the processes driving unrest. This identification and discrimination of sources driving volcanic unrest via mathematical modelling of surface data is of vital importance for hazard and risk characterisation, given the different connotations associated with magmatic and non-magmatic unrest, and plays a major role in probabilistic eruption forecasting (Rouwet et al. 2014).

\section{Application to Eruption Forecasting}

The primary objective of the case studies was to develop advanced geodetic models to interpret spatial and temporal deformation monitoring signals, and provide better constraints on the subsurface processes causing volcanic unrest. This has been achieved by incorporating more plausible model components, such as subsurface heterogeneity, topography and temperaturedependent mechanics, to relax the assumptions that hinder analytical models and maintain consistency with inferences from geophysics, geology and petrology. Crucially, this highlighted the importance of pressure-time functions and inelastic rheology in deciphering temporal deformation patterns. In turn, a more thorough understanding of how a volcanic system behaves through time will benefit eruption forecasting, as quantitative estimates of key parameters such as magma supply rate and mechanism can be deduced.

When only considering the spatial deformation pattern, this work has further demonstrated some of the pitfalls associated with models assuming homogeneous, elastic, half-spaces (e.g., Mogi 1958). Crustal heterogeneity significantly effects the horizontal and vertical location of a deformation source by altering the subsurface strain distribution. Surface strain partitioning by complex topography is equally important, such as at steep-sided stratovolcanoes. The Cotopaxi case highlighted complex partitioning behaviour along deep ravines and adjacent lava flow ridges. If ground-based geodetic monitoring sites are positioned at localities with steep topographic gradients, surface strain partitioning plays a first-order role and needs to be accounted for during data modelling. Consequently, estimates of source parameters from generic, analytical models which cannot account for heterogeneities or complex topography may skew eruption forecasting and risk mitigation 
efforts. On the other hand, more reliable deformation source locations from numerical models can be used to better estimate where and when an eruption might occur, and the associated hazard. It should also be pointed out that data limitations at some volcanoes may prevent complex numerical models being used, in which case simpler models may be the only option and their results should be carefully scrutinised and only applied cautiously to further analyses.

\section{Conclusions}

The case studies provide new interpretations of volcanic processes during intra-eruptive and non-eruptive unrest. They also provide observations for distinct magmatic settings, thus contributing to the ongoing global comparisons of deformation and unrest, and the process of pattern recognition for identification of eruption precursors. The incorporation of multi-disciplinary data into integrated geodetic models has closed the gap between observations and interpretations of volcanic deformation and gravimetric changes. This will help to improve eruption forecasting as it moves away from a qualitative approach towards incorporation of more quantitative data derived from well-constrained physical mechanisms.

Acknowledgements Work presented herein has received funding by the European Commission (FP7; Theme: ENV.2011.1.3.3-1; Grant 282759: VUELCO). We are very grateful to Alvaro Guevara and Irving Munguía Gonzalez for their help translating Spanish, and to two anonymous reviewers for their constructive comments.

\section{Glossary Terms}

Deformation the action of changing the shape of a physical object (e.g., a volcano) under the influence of some stress.

Elastic rheological behaviour in which an applied stress causes an immediate strain that is $100 \%$ recoverable when the stress is removed. See also rheology and viscoelastic.
Finite Element Method/Analysis a numerical modelling technique that subdivides an entire problem into a set of smaller 'elements'. Mathematical problems are then solved in each of the elements and combined together to calculate the response of the whole object.

Geodesy applied mathematics with the aim of measuring the geometric spatial representation of the Earth and its gravitational field in time-varying three-dimensions, as well as their orientation in space. Volcano geodesy specifically deals with recording the spatial and temporal patterns of crustal deformation and gravimetric changes in volcanic settings.

Gravimetry field of geophysics devoted to observing, processing and interpreting minute changes in the Earth's gravitational field.

Hydrothermal system an area in which heat and fluids from a partially molten magmatic body interact with a multi-phase groundwater system, causing chemical and thermal (heating) perturbations to the water.

Mechanics (crustal, thermal) the branch of physics that studies how stress can effect a physical object. Crustal mechanics relates to the values of the material parameters that describe the mechanical behaviour of the Earth's crust. Thermal mechanics relates to the variation in mechanical material properties due to changes in temperature.

Model (inverse, forward) a simulation of a process. Inverse models solve 'backwards' to determine optimal model parameters that fit a set of data. Forward models use predefined constant input parameters to calculate the expected model response.

Rheology (crustal) the behavioural response of the Earth's crust to forces that act upon or within it. See also elastic and viscoelastic.

Strain the change in dimension of an object (e.g., $\Delta X$ ) relative to the original dimension of the object (e.g., $X$ ). It has no units, as the units cancel: $\Delta X / X$.

Stress a measure of force per unit area, with the unit of pascals, Pa. $1 \mathrm{~Pa}=1 \mathrm{~N} / \mathrm{m}^{2}$. 
Viscoelastic rheological behaviour in which an applied stress causes an elastic response, followed by a delayed (viscous) response. See also rheology and elastic.

\section{Index Terms}

Magma reservoir, deformation, gravity, GPS, InSAR, Cotopaxi, Soufrière Hills, Las Cañadas, Uturuncu, unrest, thermomechanics, modelling, finite element, inversion/inverse model, crustal mechanics, hybrid unrest, Young's Modulus, Poisson's Ratio, viscosity.

\section{References}

Annen C (2009) From plutons to magma chambers: thermal constraints on the accumulation of eruptible silicic magma in the upper crust. Earth Planet Sci Lett 284(3-4):409-416

Battaglia M, Gottsmann J, Carbone D, Fernández J (2008) 4D volcano gravimetry. Geophysics 73(6):WA3WA18

Brocher TM (2005) Empirical relations between elastic wavespeeds and density in the Earth's crust. Bull Seismol Soc Am 95(6):2081-2092

del Potro R, Dez M, Blundy J, Camacho AG, Gottsmann J (2013) Diapiric ascent of silicic magma beneath the Bolivian Altiplano. Geophys Res Lett 40(10):20442048

Fialko Y, Pearse J (2012) Sombrero uplift above the Altiplano-Puna magma body: evidence of a ballooning mid-crustal diapir. Science 338(6104):250-252

Fournier N, Chardot L (2012) Understanding volcano hydrothermal unrest from geodetic observations: insights from numerical modeling and application to White Island volcano, New Zealand. J Geophys Res 117(B11):B11208

Gottsmann J, Odbert HM (2014) The effects of thermo-mechanical heterogeneities in island-arc crust on time-dependent pre-eruptive stresses and the failure of an andesitic reservoir. J Geophys Res. doi:10.1002/ 2014JB011079

Gottsmann J, Rymer H, Berrino G (2006a) Unrest at the Campi Flegrei caldera (Italy): a critical evaluation of source parameters from geodetic data inversion. J Volcanol Geoth Res 150(1-3):132-145

Gottsmann J, Wooller L, Marti J, Fernandez J, Camacho AG, Gonzalez PJ, Garcia A, Rymer H (2006b) New evidence for the reawakening of Teide volcano. Geophys Res Lett 33(20)

Gudmundsson A (2011) Rock fractures in geological processes. Cambridge University Press, New York
Hautmann S, Gottsmann J, Sparks RSJ, Mattioli GS, Sacks IS, Strutt MH (2010) Effect of mechanical heterogeneity in arc crust on volcano deformation with application to Soufrière Hills volcano, Montserrat, West Indies. J Geophys Res 115(B9):B09203

Hautmann S, Witham F, Christopher T, Cole P, Linde AT, Sacks IS, Sparks RSJ (2014) Strain field analysis on Montserrat (W.I.) as tool for assessing permeable flow paths in the magmatic system of Soufriere Hills Volcano. Geochem Geophys Geosyst 15:2013G. doi:10.1002/C005087

Hickey J, Gottsmann J (2014) Benchmarking and developing numerical finite element models of volcanic deformation. J Volcanol Geoth Res 280:126-130

Hickey J, Gottsmann J, del Potro R (2013) The large-scale surface uplift in the Altiplano-Puna region of Bolivia: a parametric study of source characteristics and crustal rheology using finite element analysis. Geochem Geophys Geosyst 14(3):540-555

Hickey J, Gottsmann J, Mothes P (2015) Estimating volcanic deformation source parameters with a finite element inversion: the 2001-2002 unrest at Cotopaxi volcano, Ecuador. J Geophys Res Solid Earth 120 (3): $1473-1486$

Hickey J, Gottsmann J, Nakamichi H, Iguchi M (2016) Thermomechanical controls on magma supply and volcanic deformation: application to Aira caldera, Japan. Sci Rep 6(August):32691

Masterlark T (2007) Magma intrusion and deformation predictions: sensitivities to the Mogi assumptions. J Geophys Res 112(B06419)

Mogi K (1958) Relations between the eruptions of various volcanoes and the deformations of the ground surfaces around them. Bull Earthq Res Inst 36:99-134

Molina I, Kumagai H, Garca-Aristizábal A, Nakano M, Mothes P (2008) Source process of very-long-period events accompanying long-period signals at Cotopaxi Volcano, Ecuador. J Volcanol Geothermal Res 176 (1):119-133

Odbert HM, Stewart RC, Wadge G (2014) Cyclic Phenomena at the Soufrière Hills Volcano, Montserrat, The Eruption of Soufrière Hills Volcano, Montserrat from 2000 to 2010, vol 39. The Geological Society, London, pp 41-60. doi:10.1144/M39.2

Pascal K, Neuberg J, Rivalta E (2013) On precisely modelling surface deformation due to interacting magma chambers and dykes. Geophys J Int 196 (1):253-278

Pistolesi M, Cioni R, Rosi M, Cashman KV, Rossotti A, Aguilera E (2013) Evidence for lahar-triggering mechanisms in complex stratigraphic sequences: the post-twelfth century eruptive activity of Cotopaxi Volcano, Ecuador. Bull Volcanol 75(3):698

Pritchard ME, Simons M (2002) A satellite geodetic survey of large-scale deformation of volcanic centres in the central Andes. Nature 418(6894):167-171

Prutkin I, Vajda P, Gottsmann J (2014) The gravimetric picture of magmatic and hydrothermal sources driving hybrid unrest on Tenerife in 2004/5. J Volcanol Geoth Res 282:9-18 
Ranalli G (1995) Rheology of the Earth. Chapman and Hall, London

Rouwet D, Sandri L, Marzocchi W, Gottsmann J, Selva J, Tonini R, Papale P (2014) Recognizing and tracking volcanic hazards related to non-magmatic unrest: a review. J Appl Volcanol 3:1-17

Open Access This chapter is licensed under the terms of the Creative Commons Attribution 4.0 International License (http://creativecommons.org/licenses/by/4.0/), which permits use, sharing, adaptation, distribution and reproduction in any medium or format, as long as you give appropriate credit to the original author(s) and the source, provide a link to the Creative Commons license and indicate if changes were made.
Sparks RSJ, Folkes CB, Humphreys MC, Barfod DN, Clavero J, Sunagua MC, McNutt SR, Pritchard ME (2008) Uturuncu volcano, Bolivia: volcanic unrest due to mid-crustal magma intrusion. Am J Sci 308(6):727-769

Sparks RSJ, Biggs J, Neuberg JW (2012) Monitoring volcanoes. Science 335(6074):1310-1311

The images or other third party material in this chapter are included in the chapter's Creative Commons license, unless indicated otherwise in a credit line to the material. If material is not included in the chapter's Creative Commons license and your intended use is not permitted by statutory regulation or exceeds the permitted use, you will need to obtain permission directly from the copyright holder. 